\title{
Thinking outside the box - A vision of ambient learning displays
}

Citation for published version (APA):

Börner, D., Kalz, M., \& Specht, M. (2011). Thinking outside the box - A vision of ambient learning displays. International Journal Technology Enhanced Learning, 3(6), 627-642. https://doi.org/10.1504/IJTEL.2011.045450

DOI:

10.1504/IJTEL.2011.045450

Document status and date:

Published: 01/01/2011

Document Version:

Peer reviewed version

Document license:

CC BY-NC-ND

Please check the document version of this publication:

- A submitted manuscript is the version of the article upon submission and before peer-review. There can be important differences between the submitted version and the official published version of record. People interested in the research are advised to contact the author for the final version of the publication, or visit the DOI to the publisher's website.

- The final author version and the galley proof are versions of the publication after peer review.

- The final published version features the final layout of the paper including the volume, issue and page numbers.

Link to publication

\section{General rights}

Copyright and moral rights for the publications made accessible in the public portal are retained by the authors and/or other copyright owners and it is a condition of accessing publications that users recognise and abide by the legal requirements associated with these rights.

- Users may download and print one copy of any publication from the public portal for the purpose of private study or research.

- You may not further distribute the material or use it for any profit-making activity or commercial gain

- You may freely distribute the URL identifying the publication in the public portal.

If the publication is distributed under the terms of Article 25fa of the Dutch Copyright Act, indicated by the "Taverne" license above, please follow below link for the End User Agreement:

https://www.ou.nl/taverne-agreement

Take down policy

If you believe that this document breaches copyright please contact us at:

pure-support@ou.nl

providing details and we will investigate your claim.

Downloaded from https://research.ou.nl/ on date: 26 Apr. 2023 


\title{
Thinking outside the box - A vision of ambient learning displays
}

\author{
Dirk Börner*, Marco Kalz, and Marcus Specht. \\ Centre for Learning Sciences and Technologies \\ Open Universiteit in the Netherlands \\ Postbus 2960, 6401 DL Heerlen, The Netherlands \\ Phone: +31455762506 Fax: +31455762800 \\ E-mail: \{dirk.boerner, marco.kalz, marcus.specht\}@ou.nl \\ * Corresponding author
}

\begin{abstract}
With a focus on the situated support of informal and non-formal learning scenarios in ubiquitous learning environments the presented paper outlines the authors' vision of ambient learning displays - enabling learners to view, access, and interact with contextualised digital content presented in an ambient way. The vision is based on a detailed exploration of the characteristics of ubiquitous learning and a deduction of informational, interactional, and instructional aspects to focus on. Towards the vision essential research questions and objectives as well as a conceptual framework that acquires, channels, and delivers the information framed in the learning process are presented. To deliver scientific insights into the authentic learning support in informal and non-formal learning situations and to provide suggestions for the future design of ambient systems for learning the paper concludes with a research agenda proposing a research project including a discussion of related issues and challenges.
\end{abstract}

Keywords: ambient learning displays; ubiquitous learning; situated learning support; research agenda; contextualisation.

Reference to this paper should be made as follows: Börner, D., Kalz, M., Specht, M. (2011) 'Thinking outside the box - A vision of ambient learning displays', Int. J. Technology Enhanced Learning, Vol. , pp..

Biographical notes: Dirk Börner is a $\mathrm{PhD}$ candidate at the Centre for Learning Sciences and Technologies (CELSTEC) at the Open Universiteit in the Netherlands. In 2007 he graduated from the University of Applied Sciences in Dresden with a degree in Computer Science. He wrote his diploma thesis in collaboration with the department of Multimedia Communication at the Fraunhofer Institute for Computer Graphics. The thesis dealt with game-based learning applications and SCORM. Beside his work in European Projects, such as MACE, OpenScout, and STELLAR he is currently conducting research on ubiquitous learning support. In particular he focuses on the utilization of ambient information presentation in combination with mobile technology to support learners in authentic situations.

Dr. Marco Kalz is assistant professor at the Centre for Learning Sciences and Technologies (CELSTEC) at the Open Universiteit in the Netherlands. Marco has 10 years of experience in the field of technology-enhanced learning. He has worked in several national and international research projects. In the TENCompetence project he has led the training workpackage. In The OpenScout project Marco is leading the workpackage about competence services. Marco has more than 30 international publications and he serves as editorial board member, editor and reviewer of international scientific journals.

Prof. Dr. Marcus Specht is Professor for Advanced Learning Technologies at Centre for Learning Sciences and Technologies (CELSTEC) at the Open Universiteit in the Netherlands and director of the Learning Innovation Labs. He is currently involved in several national and international 
Author

research projects on competence based life-long learning, personalised information support and contextualised and mobile learning. His research focus is on Mobile and Contextualised Learning Technologies, Learning Network Services, and Social and Immersive Media for Learning.

\section{Introduction and background}

Within the knowledge society the constant update of knowledge and competences of individuals is becoming a necessity to solve some urgent problems of the $21^{\text {st }}$ century. From a lifelong learning perspective users should be enabled to participate in training and learning activities throughout their lifetime, be it within formal educational programs or non-formal respectively informal educational activities (Smith, 2009). At the same time the technical prospects are changing. The amount of mobile consumer devices is rapidly growing and predicted to be ten times higher than the amount of stationary devices (Morgan Stanley, 2009). Notably the used technology becomes also embedded into the physical environment providing a new digital layer that supplements existing facilities and architectures, ranging from automobiles, over living rooms, up to buildings that become smart. Furthermore the Mobile Internet is adopted much faster than the traditional Desktop Internet. In a rather short period of time after launching respective mobile services attracted already more users than desktop services did in a comparable period and the mobile data traffic is increasing continuously (Morgan Stanley, 2009).

This growing adoption of mobile technologies accompanied with ubiquitous connectivity as well as the increasing pervasiveness of information technology are changing the conditions for lifelong learning. Especially informal learning is becoming more and more prominent in mobile learning approaches (Ally, 2009). While rethinking the relationship of environment, technology, and learning, the promises of mobile and ubiquitous learning need to be explored to build a bridge between different contexts and situations learners are operating in. This is is strongly related to authentic learning theories and situated learning. Authentic learning "allows students to explore, discover, discuss, and meaningfully construct concepts and relationships in contexts that involve real-world problems and projects that are relevant and interesting to the learner" (Donovan, Bransford, \& Pellegrino, 1999). Situated cognition suggests that learning is naturally tied to authentic activity, context and culture (Brown, Collins, \& Duguid, 1989). Situated learning is referred to as learning that takes place in the same context as it is applied (Lave \& Wenger, 1991). Moreover Donald Schön's concept of the reflective practitioner strengthens the relation to contextualised learning and the different situated reflection perspectives (Schön, 1983; 1987) that can be taken.

In order to explore the potentials of mobile and pervasive information technology to support learning it becomes a necessity to take an interdisciplinary perspective. Hence a combination of technical models and concepts from research on ubiquitous computing, human-computer interaction, and computer-supported ubiquitous learning as well as educational theories and cognitive, respectively, social psychology research is needed.

\section{Ubiquitous learning characteristics}

Since the idea of ubiquitous computing introduced by Weiser (1999) with its subdomains pervasive and mobile computing has first appeared, the relation between people and computing devices and thus the impact of technology on learning has dramatically changed. In this context, education is considered as one of the main application areas for 
ubiquitous computing (Barbosa et al., 2008), offering mobility combined with pervasive computing functionality (Lyytinen \& Yoo, 2002). The enormous possibilities for learning still need to be investigated. On the one hand there is the promise of a seamless integration and enhanced support for learning in action and on the move. On the other hand the diversity and continuous modification of technologies, changed interaction modalities and usability requirements, the mobility of content, as well as the overwhelming amount of information challenge the learner and demand high standards for corresponding learning environments. Coping with these challenges postulates new approaches of information processing, interaction, and instructional design emerging from the characteristics of ubiquitous learning.

The ubiquitous computing approach establishes a basis for innovative informal and non-formal learning (European Commission, 2001) scenarios that are learner activated, situated as well as activity- and experience based (Beckett \& Hager, 2002) complemented by an increasing contextualisation of content. The embodied mobile learning paradigm encourages learning that is personalised, authentic, and situated (Traxler, 2009). Based upon this paradigm but differentiated in its level of embeddedness in the environment is ubiquitous learning, which conceptually rests upon the idea of ubiquitous computing. Enhancing learning environments with mobile technologies and pervasive functionality creates ubiquitous learning environments, in which different channels of information and interaction are synchronised and orchestrated by instructional designs.

Permanency, accessibility, immediacy, interactivity, situatedness, and adaptability have been identified as the main characteristics for ubiquitous learning embedded in our daily life (Ogata \& Yano, 2004). A closer examination reveals that permanency, accessibility, as well as adaptability deal with informational aspects, whereas immediacy and interactivity relate to aspects of interaction and situatedness describes an instructional design aspect. Covering all the main characteristics of ubiquitous learning, the mentioned aspects are applicable research clusters that can be explored in greater detail.

\subsection{Information Aspects}

Nowadays information is widely distributed as we are creating a constantly growing number of digital content using the means of digital media, such as pictures, videos, bookmarks, or web-log entries. Following the principles of participation, syndication, and tagging (O'Reilly, 2005), the content is distributed all over the Web and gets more and more enriched by metadata, enabling a collaborative annotation and classification. Considering the amount of available digital content finding the right information becomes more and more important (Traxler, 2009). This indicates a need of information navigation competences and postulates the support and assistance of learners in order to enable them to navigate more efficiently through information and find the right information in any given situation (Koole, 2009). One essential aspect to implement this concept is to keep the learner continuously aware about the environment he is active in, including digital content and services that are available in a real world context. Clearly the challenges are to improve the identification of relevant digital content and services, to simplify the access mechanisms, as well as to enable and facilitate contextual relationships to provide a better support for learning.

Identifying relevant content can be done using the enriched metadata, for example social classifications that offer a promising information retrieval potential (Morrison, 2008). A popular approach to combine content and functionality from two or more external sources is the creation of mash-ups. This core functionality of the Web 2.0 offers 
a great potential to enrich learning experiences and paves the way for empowering personal learning environments (Wild et al., 2009). Mash-ups ease the access to distributed information and establish new coherences never considered before. This includes linking digital content not only to people, but also to physical and virtual objects, for example by adding a geo-location to a picture. Also the other way round more and more physical and virtual objects get enriched with content and functionality and thus becoming service interfaces for digital media (Sterling, 2005). Towards an "Internet of Things" (Dodson, 2003) these links are already used to integrate physical and virtual objects into existing social networks of people or even create social networks of things, by giving these objects an identity (ThingD, 2010; Thinglink, 2010). These services massively collect things that are linked together not only by people but also by their associated digital content.

Regarding the mentioned information aspects of ubiquitous learning finding appropriate support and assistance strategies for contextualised learning sets up the focus for further research. Therefore the existing links between people, objects, and data need to be facilitated to identify digital content that is available in a real world context and thus can be contextualised to enrich the situated learning experience.

\subsection{Interaction Aspects}

The constant change of interaction modalities is closely connected to the continuous technical development and the related computational models. Starting from the electronic paradigm for interaction with the computer, over to the emergence of symbolic and textual forms as more intuitive forms of interaction, resulting in graphical representations - more and more human abilities were considered in human-computer interaction design. By gradually incorporating more skills and abilities the resulting interaction principles made computation "more widely accessible to people without requiring extensive training, and to be more easily integrated into our daily lives by reducing the complexity of those interactions" (Dourish, 2001). This process is ongoing and new concepts are emerging, as mobile technologies and pervasive computing change once more the role of computation.

An interaction approach that goes beyond conventional graphical user interfaces for personal computing is the use of ambient media in the periphery of the user. Associated with a more tangible and social interaction corresponding systems make use "of the entire physical environment as an interface to digital information. Instead of various information sources competing against each other for a relatively small amount of real estate on the screen, information is moved off the screen into the physical environment" (Wisneski et al. 1998). Thereby the used displays in the background are an addition to existing personal interfaces in the foreground, while the user attention can always move from one to the other or vice versa.

From another point of view this more embodied interaction and the rather situated than individualised design approach triggered by embedding information technology into the physical world extends the digital world beyond the desktop, thus becoming an "ambient social infrastructure" (McCullough, 2005). This aspect goes hand in hand with the call for engaging user experiences, "where technology is designed to enable people to do what they want, need or never even considered before by acting in and upon the environment" (Rogers, 2006). Carrying this idea a bit further even leads to a possible fusion of physical objects with digital information. This notion of blending the real and the digital world is connected to the concept of mixed reality, where physical and digital 
objects co-exist, interact, and enhance each other. As part of the continuum between real and virtual environments (Milgram et al., 1994) the concept produces new environments and augmentations and can be differentiated in augmented reality (covering all digitally enriched environments) and augmented virtuality (describing virtual environments that are enhanced by physical objects), although clear boundaries between the different parts of the continuum do not exist.

In a world where information is widely distributed and highly contextualised ambient systems incorporating the mixed reality concept can be used to enable the access to digital content that is available in a real world context, building on the links between people, objects, and data. Facilitating these new interaction approaches for a better ubiquitous learning support extends the research focus.

\subsection{Instructional Design}

The changed paradigms of information handling and interaction offer a strong potential to provide both powerful contextual, in situ experiences and discovery of the connected nature of information in the real world. Most notably simple augmented reality (mainly facilitated through mobile technologies) currently attracts a lot of attention and is considered as one of the future trends for learning offering exactly the described potential (Johnson et al., 2010). New technologies are adopted rapidly and digital content becomes more important for learning. Also the type of tools used for learning is changing towards social software tools and web 2.0 services (Tools for Learning, 2009). The modelling of ubiquitous learning support has been discussed in relation to the use of IMS LD and the orchestration of learning activities. Several challenges for ubiquitous learning support with IMS LD are discussed by Zervas, Gomez, Fabregat \& Sampson (2011) while Dillenbourg \& Jermann (2010) have summarized the current implications from the orchestration perspective. In a next step the implications for ubiquitous learning need to be investigated.

Following the situated learning approach (Lave \& Wenger, 1991) ubiquitous learning is embedded within activity, context, and culture. By definition this happens in particular social and physical environments that need to support the learning process. Furthermore social interaction and collaboration are essential components, as learners involved in "communities of practice" co-construct knowledge as a social process. In authentic situations the problem and its context are defining each other, while the learning process does not involve the acquisition of abstract knowledge that is out of context. Solving a problematic situation includes the identification of the problem as unresolved issue, the specification of an approach depending on the current situation the learner is in, and finally the determination of solutions or, respectively, the generation of sub-problems that break down the original problem. Thereby "the problems encountered as well as the knowledge required are all presented in their natural and authentic forms" (Ogata \& Yano, 2004).

Regarding the instructional aspect of ubiquitous learning supporting the learning process in the social and physical environment where it is happening and enabling learners to construct knowledge complements the research focus. Thereby this process can be of a personal, social, or environmental kind.

\section{Towards ambient learning displays}


Although informal learning contexts become increasingly important for lifelong learning, there is still a divide between existing (traditional) learning environments and the realworld context. The current major problem is that ubiquitous learning is not supported in its situatedness, authentic context, and social dependencies. This is due to the insufficient utilisation of the mobile capabilities of the learner and the pervasive functionality of the physical environment in which the learning takes place. Ubiquitous access to learning support fosters new opportunities, such as content filtering by context or contextualised access to interaction facilities. Context in that sense is described as a broad concept, which allows adaptation "according to the location of use, the collection of nearby people, hosts, and accessible devices, as well as to changes to such things over time." (Schilit, Adams \& Want, 1994), but might also include environment-induced aspects, for example illumination, noise, and network connectivity.

Offering a variety of display and interaction modalities that can be utilised by the learner is an actual strength of ubiquitous learning environments. Thus the learner is | almost free in the learning process. This main strength implicitly holds a major problem. Learners are confronted with missing awareness indicators reflecting the available learning support in their current environment including relevant digital content meaningful within the situation, context, or activity the learner is in. The main reason for that is the wide distribution of content among different devices, platforms, and providers. Finding the appropriate content is difficult as it often takes more time and effort than it actually benefits. Once identified, accessing the desired content is also difficult, as the different service interfaces differ in design and implementation as well as the used interaction metaphors differ among the learner's different devices, systems, and platforms. What makes it even more difficult is that digital content is often not linked and accessible in a contextualised manner (e.g., links between digital content and real-world objects). The other way round it mostly is not possible to create these links. Furthermore the threshold to reach the desired awareness gets insuperable, due to the vast amount of available content, which is constantly growing.

To sum up, the main problem is that ubiquitous learning is not supported in its situatedness and authentic context. One reason is that relevant awareness indicators reflecting the available support are missing. This is due to the wide distribution of content; the difficulties of finding and accessing appropriate content and an insufficient contextualisation of content. The depicted problems lead to derived research questions and objectives outlined in the following sections that need to be answered and accomplished.

\subsection{Research Questions}

As common techniques and traditional learning environments do not support ubiquitous learning and the required awareness for relevant resources in a sufficient way, the integral parts of ubiquitous learning support need to be examined to define the research questions and after all solve the delineated problems. More precisely this involves the acquisition, processing, and delivery of learning support framed in authentic situations. Correlating these parts with the enumerated informational, interactional, and instructional aspects of ubiquitous learning and their discussed development potentialities lead to the following broad research questions:

- Which types of digital content can support learning in ubiquitous learning environments? How can this content be condensed to create meaningful mashups? 
- Which sensors, displays, and artifacts can be used and how must they be aggregated, filtered, and implemented in ubiquitous learning environments?

- Which methods of interaction and information presentation can be used to create awareness in ubiquitous learning environments?

- How are the awareness methods assimilated and perceived in ubiquitous learning environments and what are the implications for the design?

- Does the utilisation of contextualised digital content support and enhance the learning experience in ubiquitous learning environments and what are the effects?

To formulate the research objective more specific research questions are needed, bringing into focus the distinguished characteristics of authentic learning situations including the personal and environmental sense-making process and the development of problem solving strategies.

- Which information is relevant for learners in authentic learning situations within ubiquitous learning environments and how can this information be obtained and aggregated?

- How can ambient interaction modalities improve the availability and accessibility of this information within ubiquitous learning environments?

- Is the improved availability and accessibility of relevant information an effective support in authentic learning situations?

Assembling these specific research questions taking into account the general focus on learning as well as the feasibility of their investigation, leads to the research question that the authors eventually set up to answer in further research work: What are the effects of ambient information presentation on learning in a situated learning context within ubiquitous learning environments?

\subsection{Research Objectives}

Apparently the general research objectives emerge from the intercourse with the specific research questions compiled in the previous section. Hence, the objective is to support learners in authentic learning situations within ubiquitous learning environments. They should be empowered to solve problems, generate knowledge interactively, and interact appropriately. Furthermore the learners need to be aware of their position within the community of practice they are in during the learning process as well as their progress in acquiring the constructed knowledge.

The underlying learning process, especially the personal sense-making process and the development of problem solving strategies, needs to be supported where it is happening. Enabling the learner to navigate more efficiently through information and find the right information in any situation is essential. The available information needs to be presented in authentic contexts, settings, and situations that would normally involve the represented knowledge. Furthermore this information should be moved off the screen into the physical environment making the representation as well as the interaction with it more social, tangible, and physically perceptible. More condensed, the primary objectives of further research work are as follows: 
Author

- Establish the awareness for information relevant for situated learning within ubiquitous learning environments.

- Examine the personal, social, and environmental sense-making process facilitated through ambient information presentation within ubiquitous learning environments.

- Evaluate the situated learning support in authentic learning situations on its effectiveness for learning, especially to solve problems in context.

Designing such a system the authors intend to facilitate mixed-reality information mashups of digital content and use different ambient channels to distribute this information | across contexts and devices. Finally their effects on the situated learning process, resulting in ambient systems for learning - or in other words the envisioned ambient learning displays - will be measured. As a secondary objective the research activity outcomes can contribute to a definition of functional requirements for a ubiquitous learning support framework. The framework will give suggestions and provide guidelines for the design and implementation of future ambient systems and applications for learning, easing and aiding the situated learning support.

\subsection{Provisional conceptual framework}

To accomplish the research objective and answer the research question several aspects need to be considered. The information presented in context needs to be acquired, channelled, delivered, and framed in the learning process. In this regard relevant research findings, models, design dimensions, and taxonomies have been examined resulting in a conceptual framework that provisionally defines ambient learning displays (Börner et al., 2010) and consists of parts dedicated to acquisition, channelling, delivery, and framing (see Figure 1). 
Figure 1 Provisional conceptual framework for ambient learning displays

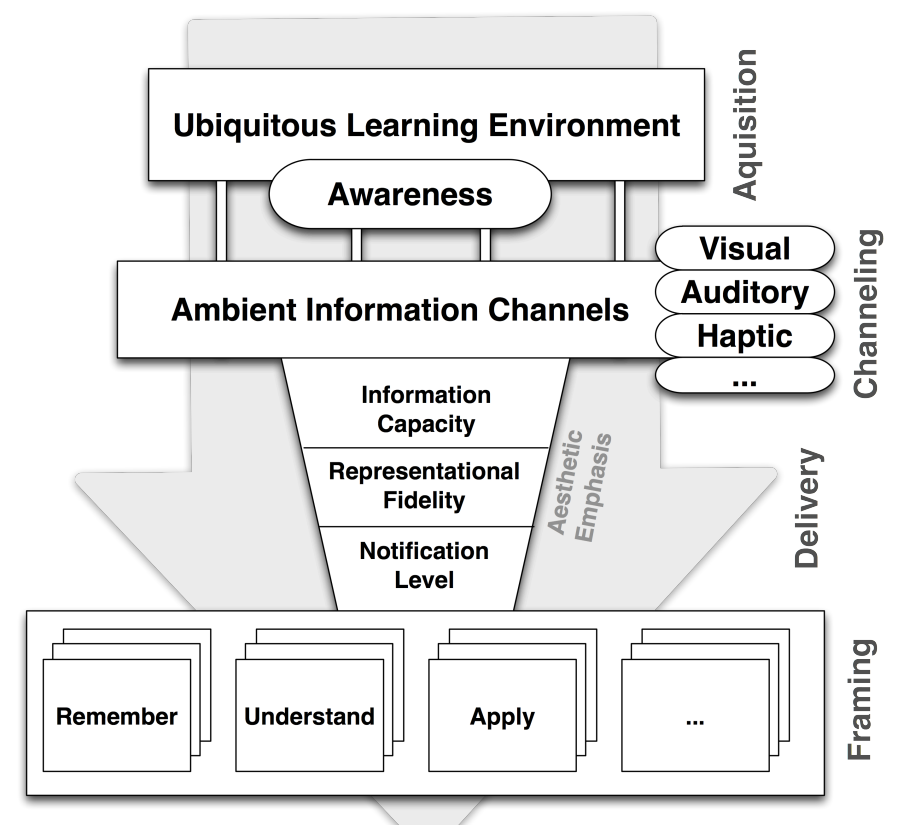

\section{Ambient Learning Displays}

Within the framework awareness as one of the key concepts for informal learning support (Syvanen, Beale, Sharples, Ahonen \& Lonsdale, 2005) is used as acquisition instrument of the information relevant for the learner within the ubiquitous learning environment (Ogata, 2009). Consequently the acquired social, task, concept, workspace, knowledge, and context awareness information sets up the conceptual framework. In order to present the acquired information in context the ambient information channels model introduced by Specht (2009) is utilised to carry on the conceptual framework. Within the model ambient channels are used to deliver information and services but also to feed information back into the system. Thereby information might be channelled into visual, auditory, haptic, odorous and respectively tasting extraditable parts. To deliver the previously channelled information within the ubiquitous learning environment ambient systems are used. Based on the comparison and discussion of existing ambient information systems by Pousman \& Stasko (2006), the four design dimensions: information capacity, notification level, representational fidelity, and aesthetic emphasis are used to design ambient systems as means of delivery. The framing of the previously acquired, channelled, and delivered information in a learning context then complements the conceptual framework. Based on the revised taxonomy of educational objectives of Anderson \& Krathwohl (2001) activities and objectives enabled by the systems are matched to the types of knowledge and the cognition processes involved. Thereby the taxonomy describes on the one hand several cognitive process dimensions ranging from remembering over applying to creating and distinguishes on the other factual, conceptual, procedural, and metacognitive knowledge.

But how would relevant information actually flow through the proposed conceptual 
Author

framework? Assuming an example setup where the users are asked to identify existing learning objects/resources available in their proximity and match them according to the context they are used in. Thereby context describes the relation of a learning scenario and the location where the scenario takes place. This task addresses a simple cognitive process dimension dealing with factual knowledge. An ambient system fed with information reflecting the awareness needs of the users operating within the environment would be used to support the task. Depending on the activity (derived from the addressed cognitive process dimension) that needs to be supported, this information is channelled through ambient information channels utilising different means and modalities to deliver appropriate input for the ambient systems.

In such a setup creating workspace awareness could mean to use an ambient visualisation method to describe possible learning scenarios. Concerning knowledge awareness ambient audification methods could be used to create awareness when someone enters the environment, who created a certain learning object/resource and thus might assist with the matching. And to provide a last example, vibration could be used as a possible ambient haptification method to create context awareness reflecting the spatial proximity of the learning object/resource to its learning scenario, respectively the designated location.

\section{Research agenda}

Heading towards the implementation and manifestation of the envisioned ambient learning displays an agenda for further research work has been set up incorporating the outlined research questions and objectives. Based on this agenda the authors propose a research project described in the following sections depicting an experimental design as well as a usable evaluation technique.

In preparation of the research project a small-scale study (Börner, Glahn, Stoyanov, Kalz $\&$ Specht, 2010) has already been conducted to gather opinion of experts in the field of mobile and ubiquitous learning on the educational problem that can be solved by mobile learning. For this purpose Concept Mapping (Trochim, 1989) has been chosen as an appropriate method. The method provides a structured approach to identify the experts' opinion on a given domain, including both qualitative techniques and multivariate analysis approaches. The result is a visual map of useful and important concepts that can then be used for further elaborations. The study revealed that the two most important problem clusters are dealing with "access to learning" and "contextual learning" aspects. Focusing on these problem clusters and the covered problem descriptions in detail gives valuable insights on the educational characteristics that define mobile and ubiquitous learning. For the presented research agenda these results of the study are used both as indicators for the educational focus and as an instrument to validate the research findings.

The actual research design will begin with an extensive literature review covering in general the aspects discussed in section 2 with a clear focus on ambient systems. Regarding ambient systems there is a particular interest in existing applications used to support personal, social, and environmental sense-making processes; derived patterns for the design of such applications; and criteria and techniques that have been used for evaluation. It is expected to find a large number of ambient systems that simply represent information rather than supporting more complex cognitive processes. In any case it needs to be investigated if and how the applications are used within learning scenarios and how they are evaluated on their effectiveness for learning. 


\section{Thinking outside the box - $A$ vision of ambient learning displays}

Towards a profound conceptual framework that finally establishes the basis to build prototypes for an experimental design, a lot of work has already been done as described in section 3.3. Under the assumption that the information presented in context needs to be acquired, channelled, delivered, and framed in the learning process, relevant research findings, models, design dimensions, and taxonomies have been examined. Though the outlined provisional conceptual framework for ambient learning systems is still subject of modifications. Most probably the modifications will be due to the gathered insights from the literature review of existing ambient systems for learning as well as the evaluation techniques for respective applications.

\subsection{Experimental Design}

Based on the prior literature review and the resulting conceptual framework analysis an experimental design will be used to evaluate the prototypes built upon the conceptual framework. Prior to the design it is planned to conduct formative studies to gather insights on the specific usability needs and requirements of ambient systems and aid the design process. Then a setup of ambient system prototypes, addressing specific cognitive process dimensions, varied on the values of single design dimensions will be designed and implemented. There is a particular interest in the effects on learning affected by the way the ambient systems present information. The goal is to unveil in summative studies how the single prototypes and prototype setups perform. The experimental design is oriented on design-based research (Baumgartner et al., 2003), following a recurrent cycle of designing an experiment, implementing the experiment, and evaluating the results in order to review the experimental design again.

An example setup for such an experiment can be illustrated as follows: the ambient system is fed with information reflecting the awareness needs of users operating within the ubiquitous learning environment. Depending on the activity (derived from the addressed cognitive process dimension) that needs to be supported, this information is channelled through ambient information channels to deliver appropriate input for the ambient systems. Each ambient design dimension can be varied on its distinguished values. In this first experimental cycle the effect when manipulating these values on each dimension will be measured, to figure out if and how this influences the performance of the given activity and thus is effective for learning or not.

A possible hypothesis in such an experiment would be that ambient systems with a low information capacity, an abstract representational fidelity, and a level of notification that only makes aware, benefit the cognitive process dimension 'remember'. To test this hypothesis the single ambient design dimensions would then be varied and compared to each other. To do so quantitative and qualitative data using data logs, questionnaires, as well as a specific evaluation technique described in the next section will be collected.

\subsection{Evaluation Technique}

To investigate and determine if the envisioned experimental prototypes are suitable to support learners in authentic learning situations within ubiquitous learning environments an appropriate evaluation technique is needed. Due to the nature of ubiquitous learning finding suitable techniques is rather difficult. Users constantly move across contexts, change environments, and usually are not restricted to act within a closed testbed for evaluation. Thus the experienced conditions cannot be controlled completely nor kept similar. Therefore traditional evaluation techniques, such as pre-test/post-test designs, are not sufficient. Instead the evaluation has to be done also in situ, taking into account the 
current context, environment, and conditions the user is experiencing.

The challenge though is to find an appropriate technique that allows measuring the effects in authentic learning situations. For ambient systems as well as ubiquitous learning applications corresponding methods will be explored during the literature review. One method that is already in the focus of attention is the Experience Sampling Method. The method has already been applied and examined for ubiquitous computing applications. Derived from the field of psychology the technique is especially effective for learning about situations and person-situation interactions and allows to "take place in situ, involve several participants, take place over time, and collect both qualitative and quantitative data" (Consolvo \& Walker, 2003). The technique uses several brief adoptable questionnaires to let the participants report about their current activity and the situation they are in. The participants are alerted in situ and asked to respond by filling out a brief questionnaire. Traditionally used to evaluate aspects like emotion, performance, or social interaction, the technique seems also sufficient to evaluate ambient systems for learning.

Coming back to the example given in the previous section the method could be applied as follows. Each participant is assigned to a specific task, which is to identify and match existing objects/resources. To complete the task, the participants need to perform certain actions. In the moment they completed the assigned task an event is triggered that delivers an adapted questionnaire taking into account the current situation and context the participant is in. The participants are then asked to indicate, for example which information supported them to solve the task or which ambient system supported them to solve the task. Using statistical methods on the surveyed qualitative and quantitative data finally allows measuring the effectiveness of the ambient information presentation for learning through the performance of the participants.

\section{| 4.3 Discussion}

While elaborating the research project some issues and challenges mainly related to the undetermined target domain used to conduct the experiments, the evaluation of ubiquitous scenarios in laboratory settings, as well as the importance of aesthetic design for the experiments emerged. The issues related to the application domain are rather complex. Quite reasonably the chosen application domain has a great influence on the learning conditions. Authentic and situated learning usually occurs when learners are strongly related to the placement they are active in and at the same time far away from traditional (mostly formal) learning capabilities they would usually make use of. The characteristics of the current placement and the requirements of the learners have in fact a great influence on the assumptions the learners may have, the conditions they may find in situ, as well as technical constrains of the settings. The chosen domain has an impact on the conceptual framework and hence on the experimental design and the evaluation and thus has to be chosen carefully.

The evaluation of ubiquitous scenarios in laboratory settings is self-contradictory. While ubiquitous computing and the derived ubiquitous learning scenarios are characterised by the "anywhere, anytime" paradigm, laboratory settings per se exclude these features as they postulate the full control of all confounding variables. Evaluation techniques need to take into account the current context, environment, and conditions the user is experiencing within the situation that is observed. One possible solution has already been mention in section 4.2 describing a method already used to evaluate ubiquitous computing applications (Consolvo \& Walker, 2003). Still other available 
methods need to be investigated and verified on their adequacy for the evaluation of ubiquitous learning applications and thus ambient systems for learning.

Another issue is the importance and influence of an aesthetic design especially when heading for an end-user product. The aesthetic emphasis is one of the dimensions affecting the design of ambient systems (Pousman \& Stasko, 2006). Within the presented research project this dimension will be mostly ignored. The reason for that is mainly the focus on evaluating the effects of ambient information presentation on learning and learning support rather than actually designing end-user products. In this context emphasising the aesthetics design dimension of ambient systems too much is simply not feasible for the research project, but definitely needs to be considered when applying the outcomes to actual learning scenarios.

\section{Conclusions}

The presented paper outlines the authors' vision of ambient learning displays - enabling learners to view, access, and interact with contextualised digital content presented in an ambient way. The vision is based on a detailed exploration of the characteristics of ubiquitous learning and a deduction of informational, interactional, and instructional aspects to focus on. Towards the vision essential research questions and objectives as well as a conceptual framework that acquires, channels, and delivers the information framed in the learning process are presented. Furthermore a research agenda proposing a research project is presented. This research project offers rich opportunities for the design of environments following the mobile and ubiquitous learning paradigm, which gain in importance for Technology-Enhanced Learning (TEL). Recently the EU-funded project STELLAR identified the grand research challenges for the future of TEL. As a guideline three themes have been formulated: connecting learners, orchestrating learning, as well as contextualising virtual learning environments and instrumentalising learning contexts (STELLAR, 2009). The authors' vision of ambient learning displays is strongly devoted to the contextualisation theme; implicating manifold overlaps with the other themes. Therefore the main research outcomes will also flow back into the contextualisation theme. The main idea behind the theme is to encourage situated learning, while supporting the learner's mobility. Building on that, the key research questions in this theme are:

- How can new forms of contextualised learning enable novel experiences for learners and for development of human competences?

- How to support the mobility of the learner in distributed and multi environment learning settings, like the transition between real and virtual contexts?

- Which standards are needed to achieve interoperability and reusability of learning resources in this field? How to harmonise the existing learning standards?

Comparing these key research questions with the presented vision, clarifies the relevance within the field. The authors' vision of ambient learning displays highlights the challenges and explores the possibilities that lie in the convergence of mobile and ubiquitous learning in combination with the utilisation of contextualised digital content as valuable resources to support learning.

Furthermore, the outlined research project delivers new scientific insights into the 
Author

authentic learning support in informal and non-formal learning situations. Within ubiquitous learning environments the project will investigate if there is a measureable benefit utilising ambient information presentation for a contextualised learning support. From a practical point of view this research will flow into a framework that gives guidelines for the future design of ambient systems for learning.

\section{References}

Ally, M. (2009). Mobile Learning: transforming the delivery of education and training. Edmonton, Canada: AU Press.

Anderson, L. W., \& Krathwohl, D. R. (Eds.). (2001). A taxonomy for learning, teaching and assessing: A revision of Bloom's Taxonomy of educational objectives (Complete edition). New York, USA: Longman.

Barbosa, J., Hahn, R., Rabello, S., \& Barbosa, D. (2008). Local: a model geared towards ubiquitous learning. In Proceedings of the 39th SIGCSE technical symposium on Computer science education, 432-436. ACM.

Baumgartner, E., Bell, P., Brophy, S., Hoadley, C., Hsi, S., Joseph, D., et al. (2003). Design-Based Research: an emerging paradigm for educational inquiry. Educational Researcher, 32(1), 5-8.

Beckett, D. \& Hager, P. (2002) Life, Work And Learning: Practice in Postmodernity, London: Routledge.

Börner, D., Glahn, C., Stoyanov, S., Kalz, M., Specht, M. (2010). Expert concept mapping study on mobile learning. Campus-Wide Information Systems, 27(4), 240-253.

Börner, D., Kalz, M., \& Specht, M. (2010). A Conceptual Framework for Ambient Learning Displays. In B. Chang, T. Hirashima, \& H. Ogata (Eds.), Joint Proceedings of the Work-in-Progress Poster and Invited Young Researcher Symposium for the 18th International Conference on Computers in Education (pp. 34-36). November, 29 - December, 3, 2010, Putrajaya, Malaysia: Asia-Pacific Society for Computers in Education.

Brown, J., Collins, A., \& Duguid, P. (1989). Situated Cognition and the Culture of Learning. Educational Researcher, 18(1). 32-42.

Consolvo, S., \& Walker, M. (2003). Using the Experience Sampling Method to Evaluate Ubicomp Applications. IEEE Pervasive Computing, 24-31.

Dillenbourg, P. \& Jermann, P. (2010). Technology for Classroom Orchestration. In , Khine, M. S. \& Saleh, I. M. (Eds.): New Science of Learning, p. 525-552.

Dodson, S. (2003). The internet of things. The Guardian, 10/09/2003. Retrieved from http://www.guardian.co.uk/technology/2003/oct/09/shopping.newmedia

Donovan, M. S., Bransford, J. D., \& Pellegrino, J. W. (1999). How People Learn: Bridging Research and Practice. Washington D.C., USA: The National Academies Press.

Dourish, P. (2001). Where the action is - The foundations of Embodied Interaction (2004 ed.). Cambridge, USA: The MIT Press. 
Thinking outside the box - $A$ vision of ambient learning displays

European Commission (2001). Communication: Making a European Area of Lifelong Learning a Reality. Retrieved from http://www.euractiv.com/en/education/lifelong-learning/article-117516

Johnson, L. F., Levine, A., Smith, R. S., \& Stone, S. (2010). 2010 Horizon Report. Austin, USA: The New Media Consortium.

Koole, M. L. (2009). A Model for Framing Mobile Learning. In M. Ally (Ed.), Mobile Learning: transforming the delivery of education and training. Edmonton, Canada: AU Press.

Lave, J., \& Wenger, E. (1991). Situated Learning. Legitimate peripheral participation. Cambridge, UK: Cambridge University Press.

Lyytinen, K., \& Yoo, Y. (2002). Introduction: Issues and challenges in ubiquitous computing. Communications of the ACM, 45(12), 62-65.

McCullough, M. (2005). Digital Ground: Architecture, Pervasive Computing, and Environmental Knowledge. Cambridge, USA: The MIT Press.

Milgram, P., Takemura, H., Utsumi, A., \& Kishino, F. (1994). Augmented Reality: A class of displays on the reality-virtuality continuum. In Proceedings of Telemanipulator and Telepresence Technologies, Vol. 2351, 282-292.

Morgan Stanley (2009). Mobile Internet Report. December 2009. Retrieved from http:/www.morganstanley.com/institutional/techresearch/

Morrison, J. (2008). Tagging and searching: Search retrieval effectiveness of folksonomies on the World Wide Web. Information Processing \& Management, 44(4), 1562-1579.

Ogata, H., \& Yano, Y. (2004). Context-aware support for computer-supported ubiquitous learning. In The 2nd IEEE International Workshop on Wireless and Mobile Technologies in Education, 27-34.

Ogata, H. (2009). Assisting Awareness in Ubiquitous Learning. In Proceedings of the IADIS Mobile Learning 2009, 21-27. IADIS.

O'Reilly, T. (2005). What Is Web 2.0. Retrieved from http://oreilly.com/pub/a/oreilly/tim/news/2005/09/30/what-is-web-20.html

Pousman, Z., \& Stasko, J. (2006). A taxonomy of ambient information systems: four patterns of design. In Proceedings of the working conference on Advanced visual interfaces, 67-74. ACM.

Rogers, Y. (2006). Moving on from Weiser's Vision of Calm Computing: Engaging UbiComp Experiences. In UbiComp 2006: Ubiquitous Computing, 404 - 421. Springer

Schilit, B., Adams, N., \& Want, R. (1994). Context-aware computing applications. In Workshop on Mobile Computing Systems and Applications, 85-90. IEEE.

Schön, D. (1983) The Reflective Practitioner. How professionals think in action. London, UK: Temple Smith.

Schön, D. (1987) Educating the Reflective Practitioner. San Francisco, USA: JosseyBass.

Smith, K. (2009) Looking again at non-formal and informal education - towards a new 
Author

paradigm . Encyclopedia of Informal Education. Retrieved from http://www.infed.org/biblio/non formal paradigm.htm

Specht, M. (2009). Learning in a Technology Enhanced World. Maastricht, The Netherlands: OCÉ.

STELLAR (2009). The STELLAR Network of Excellence. Retrieved from http://www.stellarnet.eu/

Sterling, B. (2005). Shaping Things. Cambridge, USA: The MIT Press.

Syvanen, A., Beale, R., Sharples, M., Ahonen, M., \& Lonsdale, P. (2005). Supporting Pervasive Learning Environments: Adaptability and Context Awareness in Mobile Learning. In IEEE International Workshop on Wireless and Mobile Technologies in Education, 251-253. IEEE.

ThingD (2010). Thing Daemon. Retrieved from http://www.thingd.com/

Thinglink (2010). Thinglink. Retrieved from http://www.thinglink.org/

Tools for Learning (2009). Top 100 Tools for Learning 2009. Retrieved from http://www.c4lpt.co.uk/recommended/

Traxler, J. (2009). Current State of Mobile Learning. In M. Ally (Ed.), Mobile Learning: transforming the delivery of education and training. Edmonton, Canada: AU Press.

Trochim, W. (1989). An introduction to concept mapping for planning and evaluation. In W. Trochim (Ed.), A Special Issue of Evaluation and Program Planning, 12, 1-16.

Weiser, M. (1999). The Computer for the 21st Century. ACM SIGMOBILE Mobile Computing and Communications Review, 3(3), 3-11.

Wild, F., Kalz, M., Palmér, M., \& Müller, D. (Eds.). (2009). Mash-Up Personal Learning Environments. In Proceedings of the 2nd Workshop MUPPLE'09. CEUR.

Wisneski, C., Ishii, H., Dahley, A., Gorbet, M., Brave, S., Ullmer, B., et al. (1998). Ambient displays: Turning architectural space into an interface between people and digital information. In Lecture Notes in Computer Science, Vol. 1370, 22-32.

Zervas, P.,Gomez, S., Fabregat, R. \& Sampson, D. (2011). Tools for Context-Aware Learning Design and Mobile Delivery, In Proc. of the 11th IEEE International Conference on Advanced Learning Technologies (ICALT 2011), Athens, Georgia, USA, 6-8, July 2011. 